were used on plants, and none that there were cooking fires or digging sticks at that time.

Wrangham interprets various anatomical traits of humans - small mouths, small gapes, weak jaws, small teeth and a short digestive system - as adaptations to eating soft, highdensity food with little fibre in it. Are these truly adaptations to cooked food?

In 1995, Leslie Aiello and Peter Wheeler suggested that increased meat-eating caused the increase in hominin brain size about 2 million years ago. They proposed that a meatrich diet accessed with stone tools permitted guts to become smaller, freeing up energy for brain growth. Primates with smaller guts consistently have larger brains, and humans are the extreme case of small guts and large brains, they said. Their hypothesis is compelling.

Wrangham argues that lumps of raw meat are difficult to digest and protein intake must be balanced with carbohydrate intake. Carbohydrates can be obtained from fat, marrow, brains, fruits and nuts, and are abundant in foods happily eaten raw by baboons, chimps and warthogs - such as corms, rhizomes and tubers of savannah plants - so Wrangham's dismissal of these sources of carbohydrates is unpersuasive.

Fire has other advantages, Wrangham observes. Sleeping on the ground at night was dangerous for hominins and a fire kept predators away. True, but antelopes sleep on the ground and have not yet invented fire or cooking.

Wrangham's analysis of the effect of cooking on humans is stronger. Cooking may have promoted a division of labour by sex. Large, prized food items hunted by males were taken home and shared, as were large vegetable items, such as tubers, gathered by females. Because females have babies, they often took on the tasks of foraging for staple vegetable foods and cooking.

Pair-bonding is another component of Wrangham's scenario. It ensures that the male hunter will have something to eat if he returns empty-handed, and reassures him that the baby he feeds is his. Pair-bonding assures the female gatherer that someone will contribute high-protein items to her baby. Because fires are visible for long distances, they may draw food thieves, so pair-bonding also gives protection to the cooks.

Wrangham's thinking about the effect of food choices on society is interesting, but his attempt to superimpose his hypothesis on to the early fossil and archaeological record is unconvincing.

Pat Shipman is professor of anthropology at Penn State University, University Park, Pennsylvania 16802, USA.

e-mail: pls10@psu.edu

\title{
Our changing body image
}

\section{Assembling Bodies: Art, Science and Imagination \\ Museum of Archaeology and Anthropology, Cambridge, UK Until November 2010}

A gleaming transparent head, studded with stainless-steel screws and embedded with microchips, sits immovable on its plinth. Unnervingly, its left eye looks real: lidless, it flickers in mute appeal as if someone were trapped inside. The Head of the Blue Chip II by Dianne Harris is one of several artworks commissioned by the Museum of Archaeology and Anthropology in Cambridge, UK, to complement the historical - and indeed prehistoric - artefacts that make up its current exhibition, Assembling Bodies.

Harris's head speaks of a possible future in which the mind might become as readable as your computer's hard drive. Such a transformation would surely take place under academic scrutiny. But how can we know of the past changes in belief that have shaped our view of the human body, such as those that led our Bronze Age ancestors to cease burying dead bodies and instead cremate them?

Scholars in different disciplines from the universities of Cambridge and Leicester, UK, have been funded by the Leverhulme Trust to explore these and other questions; Assembling Bodies is the publicly visible outcome. Curators Anita Herle, Mark Elliott and Rebecca Empson have brought ancient and modern cultural and scientific artefacts together with contemporary artists' responses to perennial questions about our material being. Clustered around seven themes, the exhibits, many loaned by other institutions, range from classical sculptures to a model of DNA, and from anatomical drawings and scientific instruments to an installation of string bags from Papua New Guinea.

The exhibition's section on genealogies contains one of the 119 volumes of the printed 'library' of the human genome commissioned by the Wellcome Trust. We see that attempts to codify human kinship in written form are not new, with a display of John Speed's early seventeenth-century Bible open at the genealogy he drew to link Adam to the Virgin Mary.

Measurement and classification were the foundations of anthropology as a professional discipline, and the museum draws on its own collections to show how the drive to define racial and psychological types could be subverted by its own methods. Alfred Cort Haddon's 1898 expedition to the Torres Strait islands between Australia and Papua New Guinea reported that, similar to modern geneticists, they found larger variations in physical measurements within the community of islanders than between the islanders and the expedition members. The sculptor Marguerite Milward made a collection of portrait busts in the 1930s to illustrate different Indian races, castes or tribes. She seems complicit with both colonial and Indian elites in justifying social stratification; yet standing in front of the pallid plastercasts, their individuality is what sticks in the mind.

What can and cannot be done with bodies is constrained by changing laws and customs. An Act for Preventing the Horrid Crime of Murder in Britain in 1751 used the threat of anatomical dissection as a deterrent to homicide.

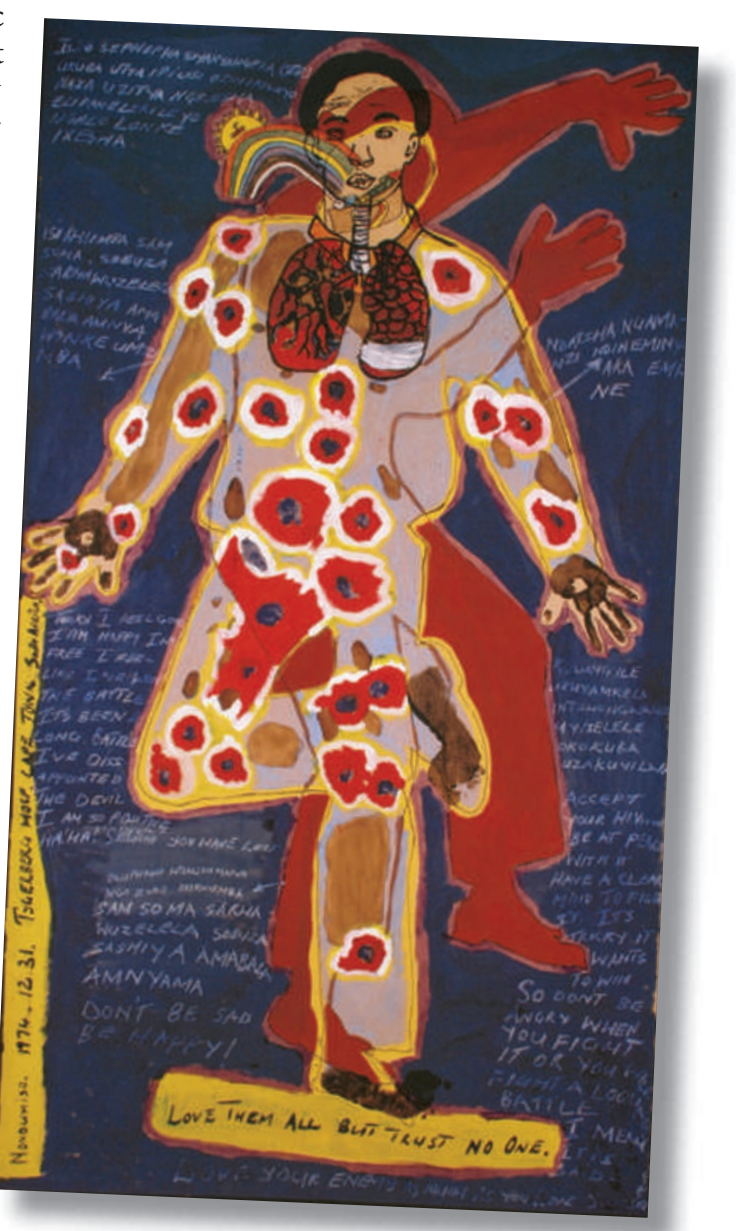

South African artist Nondumiso portrays her experience of living with HIV in Body-map (2003). 
It hangs on the wall across the room from a projection of almost 2,000 digitized cryosections that make up part of the US National Library of Medicine's Visible Human Project; they were taken from a Texan mechanic who received the death penalty for murder in 1993. The exhibition also includes a copy of the Guidance for the Care of Human Remains in Museums 2005. Appropriately, a funeral effigy from Vanuatu in the South Pacific, known as a rambaramp, contains the skull of its subject but is displayed with the permission of the community from which it was collected.

The idea that we all have multiple bodies, each made visible by the technologies used to explore them, is expressed in five lifesized body maps created by the Bambanani Women's Group in South Africa to document their experience of living with HIV/AIDS and its treatment. Within an outline tracing of her own body, each woman has illustrated her feelings about what is going on inside it, mixing biomedical, social, religious and moral perspectives.
Hanging above the central atrium is Jim Bond's Anamorphic Man. The parts of the sculpture, constructed of steel wire at vastly differing scales, appear disjointed and meaningless until the viewer moves to the single viewpoint from which the assembly coheres as a human figure. Assembling Bodies achieves the same trick, offering visitors an opportunity to make sense of the human enterprise of exploring and representing their material selves. Georgina Ferry is a writer based in Oxford, UK, and author of Max Perutz and the Secret of Life.

\section{Science journalism: From the newsroom}

\section{The Washington Post's national environmental reporter Juliet Eilperin and its executive editor Marcus Brauchli discuss the future of science coverage in their newspaper.}

JE: Like many news organizations, declines in advertising dollars and profits have led to The Washington Post losing dozens of reporters and editors in the past five years through early retirement offers - four on the science beat alone. How is that changing things?

MB: The most obvious effect is that we're getting by with fewer people and being more selective in committing our resources. We're also creating a new health, science and environment unit headed by Frances Stead Sellers, who will oversee a team of reporters covering these subjects nationally and locally. This will eliminate the old divisions in our newsroom and provide stronger, bettercoordinated coverage online and in the paper.

JE: How do you think science news stories have changed as a result?

MB: We're steering away from reporting just the facts towards analysis and contextual coverage that helps readers to understand crucial issues. We need to explain what's happening, but we also need to tell general readers and policy-makers what some event or discovery means. This is where we can bring a level of expertise to science coverage that most news organizations cannot.

The biggest challenge is to avoid bias. Yes, we encourage analysis and expertise from our writers; no, we don't want to use our interpretative skills and authority in a way that undermines our commitment to being open-minded and fair.

JE: For years, embargoed scientific papers have driven the news cycle. Should we be moving away from this sort of coverage to emphasize unique content instead?

MB: We'll continue to cover important scientific papers - and we'll always endeavour to put them in context, bringing the expertise of our science writers to the issues, rather than reporting on a single study's findings. But we also have to make choices: sometimes we'll run copy from the newswires rather than using our writers' time to cover something everybody else is covering. We've got a team of skilled reporters and we want to devote their energies to coverage that enhances the Post's mission to be for and about Washington - to serve the people and policy-makers who live and work here.

JE: That sounds as if there should be a heavy emphasis on political stories.

MB: Two of the biggest political stories this year are essentially scientific - climate change and

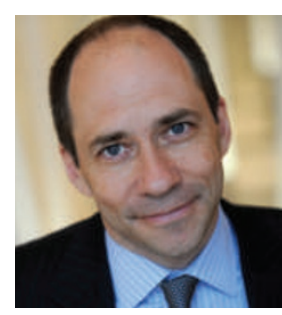

the Internet - things that move at great speed - and you might think of science as being well suited to that. But it can be incremental, too.

Look at the swine-flu story. Within hours, the blog we put together was packed with compelling coverage, fed by reporters from across the newsroom. The rapid pace of new developments - a flu case here, a school closed there - is well suited to the speed of the Internet, but then you have to guard against sensationalism, against making each advance seem more important than it

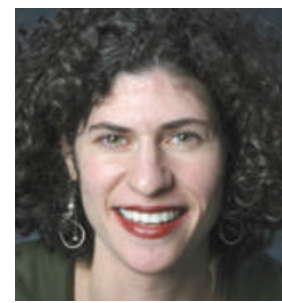

Marcus Brauchli (top) and Juliet Eilperin. is. At the same time there is a slower, incremental process of gathering information about what the virus is, or how dangerous it may become. This isn't as suitable for the web, but both trajectories need to be reported. health reform. Science is all about

JE: Do you think the web changes how stories are told?

how we live, and you can't separate that from culture or politics.

JE: News organizations are devoting more resources to their web products - your online edition now has more readers than the print edition, and you're integrating the two staffs. Do you see a distinctive place for science coverage in that transition?

MB: The ability to reach and inform readers immediately through the web is both an advantage and a huge challenge for science writing. Science created computers,
MB: Good science coverage is about much more than writing a single story; it's about using graphics to explain difficult concepts and procedures, being ready to answer readers' questions online, and using video and photo galleries to enhance our traditional storytelling. Good science writing entertains readers even as it informs them. Juliet Eilperin and Marcus Brauchli are at The Washington Post, Washington DC 20071, USA.

See Editorial, page 1033, and online at www.nature. com/news/specials/sciencejournalism. 